\title{
Aluminum-Doped Zinc Oxide Thin Films Prepared by Sol-Gel and RF Magnetron Sputtering
}

\author{
G.M. Wu*, Y.F. Chen AND H.C. LU \\ Institute of Electro-Optical Engineering, Dept. of Chemical and Materials Engineering \\ Chang Gung University, Kweisan, Taoyuan 333, Taiwan R.O.C.
}

\begin{abstract}
Zinc oxide $(\mathrm{ZnO})$ thin films have become technologically important materials due to their wide range of electrical and optical properties. The characteristics can be further adjusted by adequate doping processes. In this paper, aluminum-doped zinc oxide thin films have been prepared on glass substrates using a sol-gel route and the radio-frequency magnetron sputtering process. The stoichiometry could be easily adjusted by controlling the nanosized precursor concentration and the thickness by dip-coating cycles. On the other hand, the mixed $\mathrm{N}_{2} \mathrm{O} / \mathrm{Ar}$ plasma gas provided adequate $\mathrm{N}$ doping for the $\mathrm{RF}$ sputtering process. The results showed the low electrical resistivity of $21.5 \Omega \mathrm{cm}$ with the carrier concentration of $-3.21 \times 10^{18} \mathrm{~cm}^{-3}$ for the $n$-type aluminium-doped zinc oxide film. They were $34.2 \Omega \mathrm{cm}$ and $+9.68 \times 10^{16} \mathrm{~cm}^{-3}$ for the $p$-type aluminium-doped zinc oxide film. The optical transmittance has been as high as $85-90 \%$ in the $400-900 \mathrm{~nm}$ wavelength range. The aluminium-doped zinc oxide (2 at.\% Al) films exhibited the hexagonal wurzite structure with (002) preferred crystal orientation. The electrical characteristics were depicted by the gradual increase in N and NO that occupy the oxygen vacancies.
\end{abstract}

PACS: 81.15.Cd, 82.70.Gg, 77.55.hf

\section{Introduction}

Transparent conductive oxide (TCO) thin films such as tin-doped indium oxide (ITO) are widely used in many modern optoelectronic devices [1]. However, zinc oxide $(\mathrm{ZnO})$ presents a new class of TCO material and has become technologically important due to the wide range electrical and optical properties by adequate dopings and processing conditions, together with the high chemical and mechanical stabilities. These characteristics have made $\mathrm{ZnO}$ thin films very attractive for promising applications in solar cells, gas sensors, transducers, luminescent materials, transparent conductors, heat mirrors, and semiconductor heterojunctions [2-6].

There are several processing techniques that can provide good candidates for fabricating $\mathrm{ZnO}$ films, such as chemical vapour deposition [7], pulsed laser deposition [8], sputtering [9], and sol-gel process [10]. The desired characteristics need to be balanced with the processing costs for the practical industrial applications. The solgel method employs well-dispersed colloid particles in nanosize by hydrolysis and condensation. The gelation is formed with a crosslinked semi-solid network, and the thin film deposition process is completed by aging, drying and heat treatment. The preferred $c$-axis orientation needs to be preserved in the doped $\mathrm{ZnO}$ thin films. The desired stoichiometry can be fairly con-

* corresponding author; e-mail: wu@mail.cgu.edu.tw trolled, and the sol-gel coating can be either single-sided or double-sided. On the other, hand physical sputtering from oxide target is relatively straightforward, and the sputtering ambient control provides alternatives to adjust thin film microstructures and the defect states.

In this paper, aluminum-doped zinc oxide $(\mathrm{ZnO}: \mathrm{Al}$ or AZO) thin films have been deposited on the glass substrates by the sol-gel process, for the development of a low-cost and large-area TCO coating technique. The AZO thin films were also prepared by a magnetron sputtering system using RF power supply. Both $n$-type and $p$-type doped $\mathrm{ZnO}$ thin films were obtained on the glass substrates by the $\mathrm{Al}-\mathrm{N}$ co-doping method in the ambient of $\mathrm{N}_{2} \mathrm{O}$ and Ar. The effects of $\mathrm{N}_{2} \mathrm{O}$ partial pressure ratio on the characteristics of AZO thin films have been systematically examined. We used X-ray diffractometry (XRD), ultravioletvisible (UV-vis) spectrometry, four-point probe, and the Hall measurement technique to study their structures and properties.

\section{Experimental}

The preparation procedures of AZO thin films by the sol-gel techniques consist in three major steps, including the preparation of solution, the film coating, and the heat treatment. The clear solution was prepared from zinc acetate $\left(\mathrm{CH}_{3} \mathrm{COO}\right)_{2} \mathrm{Zn} \cdot 2 \mathrm{H}_{2} \mathrm{O}$, aluminum nitrate 9-hydrate $\mathrm{Al}\left(\mathrm{NO}_{3}\right)_{3} \cdot 9 \mathrm{H}_{2} \mathrm{O}, 2$-propanol $\left(\mathrm{CH}_{3}\right)_{2} \mathrm{CHOH}$, ethanolmaine $\mathrm{C}_{2} \mathrm{H}_{7} \mathrm{NO}$, acetic acid $\mathrm{CH}_{3} \mathrm{COOH}$, methyl acetate $\mathrm{CH}_{3} \mathrm{COOCH}_{3}$, and ethyl acetate $\mathrm{CH}_{3} \mathrm{COOC}_{2} \mathrm{H}_{5}$. The $\mathrm{Zn} / \mathrm{Al}$ ratio in the solution was designated at 
$98 / 2$ at.\%, and we used a dip-coating apparatus to accomplish the coating procedure. The withdrawing speed of the glass substrate (Corning 1737F) was set at $10 \mathrm{~cm} / \mathrm{min}$ for uniform deposition.

The dip-coated AZO/glass assembly was dried and partially annealed at a pre-heat temperature ranging between 400 and $500^{\circ} \mathrm{C}$ for $5 \mathrm{~min}$. The processing step was repeated that way for 20 times to obtain a desired thickness. After the multilayer coating, the AZO coated samples were finally post-heated at $550^{\circ} \mathrm{C}$ for $1 \mathrm{~h}$ to set the structures. The pre-heat treatment was conducted to enhance the crystal growth, while the purpose of the post-heat treatment was to increase the concentration of oxygen vacancy and thus the conductivity of the films.

For the preparation of AZO thin films by the RF magnetron sputtering, the chamber pressure was pumped up to $10^{-5}-10^{-6}$ Torr at first. The Corning $1737 \mathrm{~F}$ glass substrates were heated to $300^{\circ} \mathrm{C}$. The ambient composition effect was studied by adjusting the relative gas inlet flow rates of $\mathrm{Ar}$ and $\mathrm{N}_{2} \mathrm{O}$, while the combined flow rate was fixed at $10 \mathrm{sccm}$. All the films were deposited on the glass substrates with a constant power of $60 \mathrm{~W}$ at a sputtering pressure of $1.2 \times 10^{-2}$ Torr for $30 \mathrm{~min}$. The $\mathrm{N}_{2} \mathrm{O} / \mathrm{Ar}$ gas flow rate ratio has been maintained at $2 / 8,4 / 6$ or $8 / 2$.

The crystal orientation of the AZO thin films was investigated by Siemens D5005 XRD using $\mathrm{Cu} K_{\alpha}$ $(0.154 \mathrm{~nm})$ irradiation source. The optical transmittance spectra were revealed by Jasco V-550 UV-vis spectrometer. The electrical properties were studied by means of room-temperature Mitsubishi MCP-T600 four-point probe using the van der Pauw method. The Bio-Rad HL 5500PC Hall measurement system was employed to reveal the carrier concentration. The depth profile of the films was measured with secondary ion mass spectroscopy (SIMS) using $1 \mathrm{keV} \mathrm{O}_{2}^{+}$primary ions.

\section{Results and discussion}

The undoped $\mathrm{ZnO}$ exhibits a hexagonal wurzite structure, while the $\mathrm{Al}$ dopants replace the $\mathrm{Zn}$ lattice sites in AZO. Figure 1 shows the XRD diffraction patterns of the aluminum-doped $\mathrm{ZnO}(2$ at.\% $\mathrm{Al}$ ) films. The precursor concentration was $0.5 \mathrm{M}$. These sol-gel prepared samples were firstly annealed at various pre-heating temperatures of $400-500^{\circ} \mathrm{C}$ and then post-heated at $550{ }^{\circ} \mathrm{C}$. Three XRD diffraction peaks can be found at $31.8^{\circ}, 34.4^{\circ}$ and $36.2^{\circ}$, corresponding to (100), (002) and (101) planes in the AZO films, respectively. The hexagonal wurzite structure was preserved with (002) preferred crystal orientation on the glass substrates. The slightly higher diffraction angles were due to the smaller ionic radius of $\mathrm{Al}$ than $\mathrm{Zn}$. The thermal treatment process affected the crystallinity of the AZO films, with crystalline quality being improved by the higher pre-heating temperature at $500^{\circ} \mathrm{C}$.

The optical transmittance spectra of the sol-gel deposited AZO thin films are presented in Fig. 2 for the wavelength range of $300-900 \mathrm{~nm}$. It has been suggested

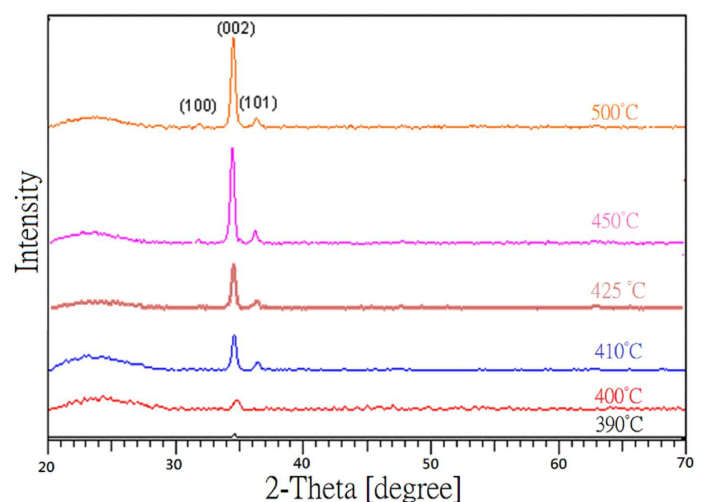

Fig. 1. X-ray diffraction patterns of the AZO $(2$ at.\% $\mathrm{Al}$ ) samples from different pre-heating temperatures. The precursor concentration was $0.5 \mathrm{M}$.

that the optical transmittance in the visible range is 80-90\%. The highest transmittance was obtained at around $90 \%$ for the lower $\left(400{ }^{\circ} \mathrm{C}\right)$ pre-heat temperature. The reduction in optical transmittance at high annealing temperature was likely to be caused by the segregated $\mathrm{Al}_{2} \mathrm{O}_{3}$ and micropores that could be formed in the AZO films during the post-deposition heating. The energy band gap was also estimated at $3.3-3.4 \mathrm{eV}$.

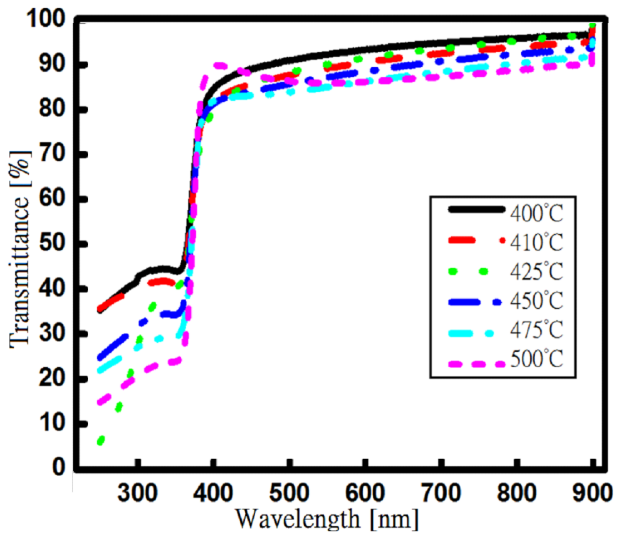

Fig. 2. The optical transmittance spectra of the AZO thin films in the wavelength range $300-900 \mathrm{~nm}$.

The electrical conductivity of AZO thin film is influenced by the oxygen vacancies and $\mathrm{Zn}$ interstitials. Both structural defects provide extra electrons as carriers, thus making great $n$-type TCO materials. The sheet resistivity of the AZO thin films with different pre-heating temperatures was analyzed by the Mitsubishi MCP-T600 four point probe at room temperature, and the data are shown in Fig. 3. The resistivity decreases with the increasing pre-heating temperature, with a clear critical temperature of $420^{\circ} \mathrm{C}$. A temperature above this critical temperature is essential for low resistivity. The thin film sample that was pre-heated at $500^{\circ} \mathrm{C}$ exhibits the sheet resistivity of $1.87 \times 10^{5} \Omega / \mathrm{sq}$. 


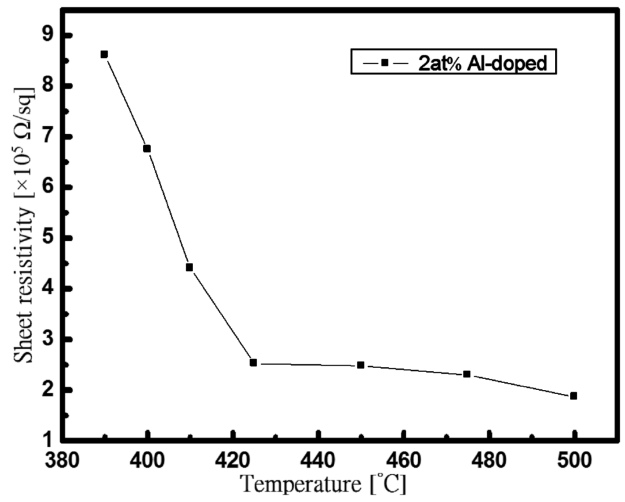

Fig. 3. The sheet resistivity results of the AZO thin films analyzed by four-point probe at room temperature.

On the other hand, when nitrogen doping is introduced during the AZO sputtering, some nitrogen atoms can replace oxygen vacancies and even deplete the formation of $\mathrm{Zn}$ interstitials. The electrical charge is balanced between $\mathrm{N}^{3-}$ and $\mathrm{O}^{2-}$ by creating electron holes. This makes it possible for the AZO films to become $p$-type TCO materials [11]. The double shallow donors can be further introduced by low-formation energy $\mathrm{N}_{2} \mathrm{O}$ molecules.

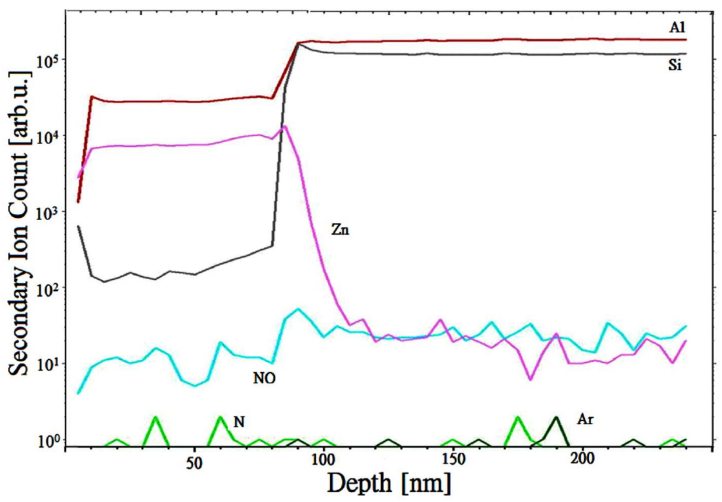

Fig. 4. The SIMS depth profiles of the mixed-gas-sputtered AZO thin films. The nominal $\mathrm{N}_{2} \mathrm{O}$ gas flow ratio was $40 \%$.

TABLE

The characteristics of AZO thin films deposited by the RF magnetron sputtering using combined $\mathrm{Ar} / \mathrm{N}_{2} \mathrm{O}$ gas ambient. The glass substrate temperature was $300^{\circ} \mathrm{C}$ and the pressure was $2 \times 10^{-2}$ Torr.

\begin{tabular}{l|c|c|c}
\hline \hline \multicolumn{1}{c|}{ Property } & Sample 1 & Sample 2 & Sample 3 \\
\hline power $[\mathrm{W}]$ & 60 & 60 & 60 \\
ambient $\left[\mathrm{N}_{2} \mathrm{O} / \mathrm{Ar}\right]$ & $2 / 8$ & $4 / 6$ & $8 / 2$ \\
resistivity $[\Omega \mathrm{cm}]$ & 21.5 & 34.2 & 67.5 \\
resistivity $[\Omega / \mathrm{sq}]$ & $1.14 \times 10^{6}$ & $1.75 \times 10^{6}$ & $4.3 \times 10^{6}$ \\
hole concentration $\left[\mathrm{cm}^{-3}\right]$ & $3.21 \times 10^{18}$ & $9.68 \times 10^{16}$ & $3.45 \times 10^{16}$ \\
type & $n$ & $p$ & $p$
\end{tabular}

Table summarizes the electrical properties of the AZO films that were deposited by the $\mathrm{RF}$ magnetron sputtering using the combined $\mathrm{Ar} / \mathrm{N}_{2} \mathrm{O}$ gas ambient inlet. The nominal $\mathrm{N}_{2} \mathrm{O}$ partial pressure ratio was $20 \%, 40 \%$ and $80 \%$. The electrical resistivity was $21.5 \Omega \mathrm{cm}$, $34.2 \Omega \mathrm{cm}$ and $67.5 \Omega \mathrm{cm}$, respectively. The gradual increase in resistivity is depicted by the increased lattice distortion caused by the additional $\mathrm{N}$ and NO that occupy oxygen vacancies. In addition, the Hall measurement results indicate a carrier concentration of $-3.21 \times$ $10^{18} \mathrm{~cm}^{-3}$ for the $\mathrm{N}_{2} \mathrm{O}-20 \%$ sputtered sample, which is still $n$-type TCO. However, the carrier concentration becomes $+9.68 \times 10^{16} \mathrm{~cm}^{-3}$ and $+3.45 \times 10^{16} \mathrm{~cm}^{-3}$ for the $\mathrm{N}_{2} \mathrm{O}-40 \%$ and $\mathrm{N}_{2} \mathrm{O}-80 \%$ sputtered samples, respectively. They both exhibited $p$-type TCO characteristics.
The SIMS depth profiles of the mixed-gas-sputtered AZO thin films are also given in Fig. 4 for the $\mathrm{N}_{2} \mathrm{O}-40 \%$ sample. It is clearly evidenced that the layer thickness is in the order of $80 \mathrm{~nm}$. There appears to be $\mathrm{Al}$ segregation at the surface.

\section{Conclusions}

The thermal treatment process affected crystallinity of AZO films. The XRD results showed clear (002)-oriented polycrystalline films on the glass substrates. The sol-gel AZO thin film pre-heated at $500{ }^{\circ} \mathrm{C}$ exhibited the sheet resistivity of $1.87 \times 10^{5} \Omega / \mathrm{sq}$. The optical transmittance in the visible range was high at $85-90 \%$. However, the transmittance could be reduced by the segregated $\mathrm{Al}_{2} \mathrm{O}_{3}$ 
and micro-pores formed in the AZO films during post-deposition heating. The RF-sputtered AZO thin films in the $\mathrm{N}_{2} \mathrm{O} / \mathrm{Ar}$ ambient gas showed increased resistivity with the $\mathrm{N}_{2} \mathrm{O}$ partial pressure ratio. The $\mathrm{N}_{2} \mathrm{O}-20 \%$ sample exhibited low electrical resistivity of $21.5 \Omega \mathrm{cm}$ with a carrier concentration of $-3.21 \times 10^{18} \mathrm{~cm}^{-3}$. On the other hand, the $\mathrm{N}_{2} \mathrm{O}-40 \%$ sample exhibited $p$-type TCO characteristics. The electrical resistivity was $34.2 \Omega \mathrm{cm}$ and the carrier concentration was $+9.68 \times 10^{16} \mathrm{~cm}^{-3}$. The characteristics were depicted by the gradual increase in $\mathrm{N}$ and NO that occupy the oxygen vacancies.

\section{Acknowledgments}

This work was partially supported by the National Science Council under research grants NSC98-2221-E182-001 and CGU-UERPD280321.

\section{References}

[1] G M. Wu, H.H. Lin, H C. Lu, Vacuum 82, 1371 (2008).

[2] C. Lee, K. Lim, J. Song, Sol. Energy Mater. Sol. Cells 43, 37 (1996).
[3] K. Matsubara, P. Fons, K. Iwata, A. Yamada, K. Sakurai, H. Tampo, S. Niki, Thin Solid Films 431, 369 (2003).

[4] S.P.S. Arya, O.N. Srivastava, Cryst. Res. Technol. 23, 669 (1988).

[5] J.K. Srivastava, L. Agrawal, B. Bhattacharyya, J. Electrochem. Soc. 11, 3414 (1989).

[6] S. Major, A. Banerjee, K.L. Chopra, Thin Solid Films 143, 19 (1986)

[7] N. Oleynik, M. Adam, A. Krtschil, J. Blasing, A. Dadgar, F. Bertram, D. Forster, A. Diez, A. Greiling, M. Seip, J. Christen, A. Krost, J. Cryst. Growth 248, 14 (2003).

[8] Y. Nakata, T. Okada, M. Maeda, Appl. Surf. Sci. 197, 368 (2002).

[9] W. Water, S.Y. Chu, Mater. Lett. 55, 67 (2002).

[10] Y. Natsume, H. Sakata, Mater. Chem. Phys. 78, 170 (2003).

[11] F. Zhuge, L.P. Zhu, Z.Z. Ye, J.G. Lu, B.H. Zhao, J.Y. Huang, L. Wang, Z.H. Zhang, Z.G. Ji, Thin Solid Films 476, 272 (2005). 